\title{
Impact of design parameters of outdoor air on the energy performance of air conditioning systems
}

\author{
Elena Malyavina*, and Olga Malikova \\ Moscow State University of Civil Engineering, Yaroslavskoe shosse, 26, Moscow, 129337, Russia
}

\begin{abstract}
The temperature and the enthalpy of the outdoor air are the main parameters of the outdoor environment, the design values of which must be assigned with a sufficient accuracy. Therefore, normalization of the design enthalpy using maps is unacceptable. The design outdoor air parameters for the warm period of the year for air conditioning in different countries are determined from the average multiyear data. However, most countries have adopted much shorter periods of exceeding the actual values of the outdoor air temperature and enthalpy than in Russia. In addition, the coasts of the most developed countries are washed by the waters of the seas and the oceans, which stabilize the weather in these countries, as a result of which the spread of parameter values from year to year in these countries is much less than in Russia having a continental climate. It is proposed to take into account the long-term excess of the calculated parameters in individual years when choosing the design temperature and enthalpy of the outdoor air for the warm period in Russia. The estimated increase in the calculated enthalpy by $4-5 \mathrm{~kJ} / \mathrm{kg}$ showed that a significant increase in the size of air conditioning units will not be required.
\end{abstract}

\section{Introduction}

The design parameters of the outdoor air are important for determining the maximum capacity of air conditioning systems, as well as the volume in the building that will be occupied by the utilities and air ducts of these systems [1-6]. In addition, the design parameters significantly affect the economic characteristics of the building, both during its construction and operation [7-12].

\section{Methods}

The methods used to process the initial climate information vary from country to country. However, they all share the same approach to the calculation of outdoor air design parameters for the warm season. This approach consists, firstly, in the fact that for each locality, the temperature and the relative humidity are considered for a multi-year period, and, secondly, as the design values from a multi-year data array, the values of parameters are assigned, above which these parameters in the average multi-year section have a pre-agreed duration.

*Corresponding author: emal@list.ru 
This duration can be set as a percentage of a year or a period, or in hours. It can also be indicated by the period when the parameters are below the design values, but this does not change anything, since the time intervals of availability and non-availability in total make the specified period of time.

The Russian standard SP 131.13330.2018 specifies the duration of non-availability of the temperature and the enthalpy of the outdoor air in the warm season as $98 \%$ and $95 \%$ of the year, i.e. 176 and 438 hours.

In the USA, the latest update of the outdoor air design parameters was published by ASHRAE in 2017 [13]. For the warm period of the year, the calculated temperatures for dry and wet thermometers are considered to be the values with $0.4,1$ and $2 \%$ non-availability of the year, which corresponds to 35,88 and 175 hours.

The method [14] adopted in the SR of Vietnam is normalized by the TCVN 5687:2010 standard. The outdoor air design parameters are given for three levels of non-availability: $0.996 ; 0.983-0.977 ; 0.960-0.954$. These levels correspond to the non-availability time intervals of $35 \mathrm{~h} /$ year, 150-200 h/year, 350-400 h/year

From the above, it follows that in the USA the non-availability levels have been adopted at a much higher level than in the Russian Federation. In addition, in the United States and the SR of Vietnam, the buildings are divided into 3 levels according to their responsibility in relation to maintaining a thermal microclimate in the rooms, and in the Russian Federation into 2 ones.

It is interesting to note that SNiP 2.04.05-86 "Heating, ventilation and air conditioning" has the table "The outdoor air design parameters", where there are data of cold and warm season temperatures, specific enthalpy and wind speed in the parameters A and B, as well as schematic maps of zoning on the value of the specific enthalpy I, $\mathrm{kJ} / \mathrm{kg}$, the outdoor air during the warm period of the year in the parameters A and B. Moreover, the air conditioning systems have been divided into 3 classes. The systems "for providing meteorological conditions within optimal sanitary or technological standards" were assigned to the second class. And if according the parameters B, for example, for Moscow the design temperature of $28.5^{\circ} \mathrm{C}$ and specific enthalpy $54 \mathrm{~kJ} / \mathrm{kg}$ have been declared, "the air conditioning systems of the second class should meet the temperature of the outdoor air for the warm period of the year at $2^{\circ} \mathrm{C}$ and the specific enthalpy at $2 \mathrm{~kJ} / \mathrm{kg}$ lower than of the parameters B". "Outside the outdoor air design parameters, the deviation of the indoor air parameters in rooms, which are serviced by the second-class air conditioning systems, is allowed to be on average $250 \mathrm{~h} /$ year for round-the-clock operation or $175 \mathrm{~h} /$ year for single-shift operation during the day time." It is interesting to note that only SNiP 41-01-2003 removed the requirements for recalculating the "B" parameters, and in SNIP 23-01-99 there was a calculated outdoor temperature according to " $\mathrm{B}$ " parameters for Moscow in the warm period of the year making $26.3^{\circ} \mathrm{C}$. The Tables with the outdoor air parameters were no longer available anywhere and, starting with SNiP 23-01-99, only maps were provided to the designer to have the specific enthalpy.

Unfortunately, air conditioning specialists have many complaints about the form of presentation and the level of standard values of the outdoor air temperature and enthalpy. Enthalpy is the main parameter for selecting cooling surfaces in the air conditioning facilities. For a reasonable assignment of the size of the air cooler, not only $\mathrm{kJ} / \mathrm{kg}$ integer values of enthalpy are important, but the tenths. Therefore, no map will replace a Table, because a map can not give the desired accuracy. The updated version of SP 60, in 2020, includes a Table with design enthalpy values for the warm period of the year for 36 cities of the Russian Federation. However, it turned out to be an absurdity, since the design temperature remained the same as it was previously obtained for another initial number of years. Now the calculated values of temperature and enthalpy have no physical connection with each other. Several outdoor air parameters are given in SP 131, which, when recalculated according to physical formulas, lead to results that differ from the data in the Table in SP 60. The enthalpy values 
presented in the maps are significantly lower than those given in the new SP 60 Table, that caused mixed opinions when discussing the new version of SP 60 before its release. Some experts were happy about the increased design enthalpy of outdoor air, which is more consistent with the realities of a hot summer weather in many cities of the Russian Federation in recent years. Others worried about the Russian economy, which they believed would be affected because of the increased size of air-conditioning units.

To check the adequacy of the levels of the outdoor air enthalpy and moisture content specified in the SP 60 [15] to the values of temperature and relative humidity given in the current SP 131, the parameters were recalculated according to the fundamental thermodynamic formulas presented in Table 1.

The Table does not include 5 cities for which there are data in SP 60, but there are no data in SP 131. In addition to the temperature and relative humidity values of the outdoor air, the design barometric pressure, as per SP 131, is also taken into account during recalculations for each city.

Table 1. Comparison of the values of the moisture content and the enthalpy of the outdoor air, obtained by recalculation from the data of SP 131 and given in SP 60

\begin{tabular}{|c|c|c|c|c|c|c|}
\hline \multirow[b]{2}{*}{ City } & \multirow{2}{*}{$\begin{array}{c}\text { The Air } \\
\text { tempera- } \\
\text { ture of } \\
0.98 \\
\text { availa- } \\
\text { bility }\end{array}$} & \multirow{2}{*}{$\begin{array}{c}\text { Air average } \\
\text { monthly relative } \\
\text { humidity of the } \\
\text { warmest month at } \\
15 \text { o'clock, } \\
\%\end{array}$} & \multicolumn{2}{|c|}{ By recalculation } & \multicolumn{2}{|c|}{ By SP 60} \\
\hline & & & $\begin{array}{l}\text { Moisture } \\
\text { content, } \\
\mathrm{g} / \mathrm{kg}\end{array}$ & $\begin{array}{c}\text { Specific } \\
\text { enthalpy, } \\
\mathrm{kJ} / \mathrm{kg}\end{array}$ & $\begin{array}{c}\text { Moisture } \\
\text { content, } \\
\mathrm{g} / \mathrm{kg}\end{array}$ & $\begin{array}{c}\text { Specific } \\
\text { enthalpy, } \\
\mathrm{kJ} / \mathrm{kg}\end{array}$ \\
\hline Astrakhan & 32 & 40 & 11.79 & 62.36 & 11.7 & 63.6 \\
\hline $\begin{array}{c}\text { Blagoveshchens } \\
\mathrm{k}\end{array}$ & 29 & 58 & 14.82 & 67.02 & 13.9 & 64.1 \\
\hline Vladivostok & 24 & 78 & 14.91 & 62.09 & 15.2 & 62.1 \\
\hline Vladikavkaz & 27 & 61 & 14.78 & 64.84 & 13.1 & 61.8 \\
\hline Volgograd & 31 & 39 & 11.03 & 59.39 & 9.4 & 56.2 \\
\hline Voronezh & 29 & 53 & 13.49 & 63.61 & 11.4 & 58 \\
\hline Grozny & 32 & 47 & 14.21 & 68.55 & 13.1 & 65.1 \\
\hline Yekaterinburg & 27 & 52 & 12.21 & 58.29 & 10.1 & 53.5 \\
\hline Irkutsk & 26 & 57 & 12.61 & 58.29 & 10.9 & 53.9 \\
\hline Kazan & 28 & 56 & 13.41 & 62.38 & 11.5 & 57 \\
\hline Kaliningrad & 25 & 60 & 11.87 & 55.37 & 11.7 & 55 \\
\hline Krasnodar & 31 & 48 & 13.51 & 65.73 & 12.6 & 64.6 \\
\hline Krasnoyarsk & 26 & 54 & 11.66 & 55.88 & 11.3 & 54.7 \\
\hline Moscow & 26 & 60 & 12.83 & 58.84 & 12.2 & 57.8 \\
\hline $\begin{array}{l}\text { Nizhny } \\
\text { Novgorod }\end{array}$ & 27 & 57 & 12.93 & 60.1 & 11.9 & 57 \\
\hline Novosibirsk & 27 & 51 & 11.47 & 56.41 & 10.9 & 54.6 \\
\hline Omsk & 28 & 49 & 11.69 & 57.99 & 10.7 & 54.3 \\
\hline Orenburg & 30 & 42 & 11.21 & 58.83 & 9,6 & 56.1 \\
\hline Perm & 26 & 54 & 11.55 & 55.57 & $11 . .2$ & 54.8 \\
\hline
\end{tabular}




\begin{tabular}{|c|c|c|c|c|c|c|}
\hline $\begin{array}{c}\text { Petropavlovsk- } \\
\text { Kamchatsky }\end{array}$ & 19 & 73 & 10.14 & 44.83 & 9 & 41.2 \\
\hline Rostov-on-Don & 30 & 46 & 12.29 & 61.58 & 11.5 & 60.6 \\
\hline $\begin{array}{c}\text { Saint- } \\
\text { Petersburg }\end{array}$ & 25 & 60 & 11.88 & 55.40 & 12.8 & 56.5 \\
\hline Saratov & 29 & 46 & 11.59 & 58.77 & 10.4 & 56.6 \\
\hline Sevastopol & 31 & 64 & 18.2 & 77.72 & 15.5 & 67.3 \\
\hline Sochi & 28 & 68 & 16.19 & 69.47 & 17.6 & 73.8 \\
\hline Stavropol & 29 & 48 & 12.66 & 61.49 & 11.1 & 58.8 \\
\hline Tyumen & 27 & 54 & 12.15 & 58.13 & 11.2 & 55.1 \\
\hline Ufa & 28 & 52 & 12.39 & 59.79 & 11.2 & 56.9 \\
\hline Khabarovsk & 27 & 62 & 14.01 & 62.9 & 14.5 & 64 \\
\hline Chelyabinsk & 27 & 52 & 11.88 & 57.46 & 10.8 & 51.8 \\
\hline Elista & 32 & 38 & 11.44 & 61.46 & 11.3 & 61.9 \\
\hline $\begin{array}{c}\text { Yuzhno- } \\
\text { Sakhalinsk }\end{array}$ & 23 & 72 & 12.71 & 55.46 & 13 & 56 \\
\hline
\end{tabular}

The recalculated results showed that, despite the taken average values of practically a maximum of the daily relative humidity of the outdoor air (at 15 o'clock), the calculated values of the specific enthalpy turned to be below the SP 60 values only in 4 cities out of 31 . The same can be said about the values of the moisture content of the outdoor air. That is, it is not necessary to suspect the SP 60 of overstatement of the parameter overvaluation. The calculation took into account the monthly average relative humidity close to the maximum daily values, and not just the average monthly values since we are talking about the indicators of the warm period of the year, which, according to common sense, are observed during the day, and not at night.

It should be said that the comparison refers to the duration of non-availability of 176 hours. Moreover, this non-availability is the average for a multiyear period. Therefore, there are years when the non-availability duration significantly exceeds 176 hours, and there are years with a shorter non-availability duration of the calculated values of the outdoor air parameters. A longer non-availability of the outdoor air design parameters means insufficient cooling capacity of air conditioning utilities during the whole period of the parameter nonavailability.

The choice of design parameters of outdoor air in the warm period of the year in most countries of the world is based on long-term measurement data at weather stations. From long-term data sets, separately about temperature and enthalpy, the part of the data with the highest values determined by the availability coefficient is thrown out, and the highest value of the remaining ones is considered calculated. Moreover, since the duration of observation of each parameter value from the accepted array is considered to be known, the proportion of high values that are discarded is measured not only as a percentage of the total array, but also in units of time. Therefore, the above-mentioned availability factor is related to time. In Vietnam, we do not consider data sets with each parameter separately, but a general set of data on the temperature and enthalpy of outdoor air observed together. From such an array, the highest values of the jointly observed parameters are thrown out, the duration of the joint observation of which corresponds to the same time security coefficient $[16,17]$. Therefore, the calculated values of the parameters are higher than when the parameters are considered separately. 
Since the values of the parameters of the outdoor environment in the Russian continental climate are different in different years, for the cold period of the year in Russia, the calculated temperatures are taken based on the lowest values in individual years.

The "year-to-year" method consists in determining, in each individual year, the values of the parameters related to different non-availability duration (apart temperature and enthalpy). Not the humidity separately, but the enthalpy, because the enthalpy is a complex indicator of the combined (temperature and humidity) effect on the cooling capacity. Therefore, we need to know the probability of exactly the parameter which makes a direct impact. Thus, the enthalpy affects the size of the air cooler in the air conditioning unit. The probability of observing the temperature level separately is necessary, since it forms the room heat gains, on which the power depends, and therefore the size of the internal recirculation air cooler in the room, for example, a fan coil. For the general conditioning process, the heat and moisture gains affect the process beam. Moreover, the maxima of heat gains and the load on the unit air cooler may not coincide in time, but should be taken into account.

We have built the temperatures and the enthalpies from individual years for each nonavailability in descending rows and for each of them we have determined the year-to-year availability. We suggested taking the 0.98 and 0.92 availabilities, as in the winter season [18].

According to the data of measurements every 3 hours at weather stations in Moscow for the years 1984-2011 at the VDNKh station [19], the Table 2 shows the 10 highest values of the enthalpy from the considered period for the specified enthalpy availability values.

Table 2. The maximum outdoor air enthalpy for the year, $\mathrm{kJ} / \mathrm{kg}$, of different time availability and non-availability, $h$, in the specified year of the average maximum enthalpy for the period under study

\begin{tabular}{|c|c|c|c|c|c|c|c|}
\hline \multirow{2}{*}{ Years } & \multicolumn{6}{|c|}{ Time availability coefficient } \\
\cline { 2 - 7 } & $\mathrm{K}_{\mathrm{a}}=1$ & $\mathrm{~K}_{\mathrm{a}}=0.996$ & $\mathrm{~K}_{\mathrm{a}}=0.994$ & $\mathrm{~K}_{\mathrm{a}}=0.989$ & $\mathrm{~K}_{\mathrm{a}}=0.97$ & $\mathrm{~K}_{\mathrm{a}}=0.95$ & \\
\cline { 2 - 7 } & \multicolumn{6}{|c|}{ Non-availability duration in the year, $\mathrm{h}$} & Duration \\
\cline { 2 - 7 } & 0 & 35 & 50 & 100 & 200 & 400 & \\
\hline 2001 & $78.5 / 40$ & $66.2 / 163$ & $65.9 / 210$ & $63.0 / 307$ & $59.4 / 437$ & $54.4 / 689$ \\
\hline 2010 & $75.2 / 28$ & $65.5 / 237$ & $64.8 / 326$ & $63.6 / 506$ & $61.3 / 767$ & $58.4 / 1132$ \\
\hline 2007 & $72.1 / 12$ & $63.9 / 99$ & $62.8 / 124$ & $60.3 / 214$ & $57.1 / 358$ & $53.6 / 633$ \\
\hline 1996 & $70.9 / 16$ & $64.3 / 50$ & $61.9 / 56$ & $56.4 / 91$ & $51.7 / 123$ & $47.5 / 238$ \\
\hline 2008 & $69.0 / 10$ & $63.8 / 74$ & $62.7 / 95$ & $59.4 / 160$ & $56.0 / 262$ & $51.1 / 436$ \\
\hline 1991 & $68.5 / 4$ & $62.7 / 61$ & $61.1 / 76$ & $57.6 / 123$ & $54.6 / 235$ & $49.9 / 383$ \\
\hline 2011 & $68.5 / 7$ & $62.2 / 66$ & $61.2 / 93$ & $59.2 / 187$ & $56.7 / 434$ & $54.1 / 783$ \\
\hline 1995 & $68.5 / 4$ & $56.7 / 18$ & $55.9 / 19$ & $53.9 / 33$ & $51.8 / 87$ & $49.1 / 277$ \\
\hline 1990 & $67.1 / 4$ & $58.0 / 25$ & $57.4 / 30$ & $51.7 / 44$ & $48.6 / 54$ & $44.8 / 136$ \\
\hline 2004 & $66.2 / 36$ & $62.1 / 52$ & $60.7 / 72$ & $58.5 / 137$ & $55.7 / 259$ & $51.7 / 484$ \\
\hline average & 65.8 & 59.9 & 58.9 & 56.5 & 53.7 & 49.9 \\
\hline
\end{tabular}

Table 2 shows the enthalpy values with the time availability indicated above in the year indicated on the left. The average value of the enthalpy for the period under review is presented in the last row of the table, the non-availability of which in specific years is followed by a slash of each value of the enthalpy [19]. 
The significant dispersion of parameter values in Moscow is explained by the continental climate. This statement is supported by the Table 3, which presents the ranges of the actual non-availability of average multiyear values of temperature and enthalpy. At the same time, the climate of most developed countries in Europe and Asia is greatly influenced by the seas and the oceans at the country coasts. Therefore, in these countries, there is a much smaller variation in the values of the outdoor air temperature and enthalpy than in the countries with a continental climate. The "maritime" countries can afford to take the outdoor air design parameters as the average of multiyear data. For the countries with a continental climate, it is important to take into account the possibility of long-term observations of the outdoor air high parameters in individual years.

Table 3. Ranges of the non-availability actual duration of the average multiyear values of the outdoor air parameters for the 10 hottest years

\begin{tabular}{|c|c|c|c|c|c|}
\hline \multirow{4}{*}{$\begin{array}{l}\text { Ranges of the non-availability duration, } \\
\text { h }\end{array}$} & \multicolumn{5}{|c|}{$\begin{array}{l}\text { Time availability coefficient in the average multi-year } \\
\text { context }\end{array}$} \\
\hline & $K_{a}=0.996$ & $K_{a}=0.994$ & $K_{a}=0.989$ & $K_{a}=0.977$ & $K_{a}=0.954$ \\
\hline & \multicolumn{5}{|c|}{ Average multi-year non-availability, $h$, in the year } \\
\hline & 35 & 50 & 100 & 200 & 400 \\
\hline $\begin{array}{c}\text { of average multi-year temperature values } \\
\text { in specific years }\end{array}$ & $20-352$ & $26-381$ & 466 & $70-581$ & $138-767$ \\
\hline $\begin{array}{l}\text { average multi-year enthalpy values in } \\
\text { specific years }\end{array}$ & $18-237$ & $19-326$ & $33-506$ & $54-767$ & $136-1132$ \\
\hline
\end{tabular}

Thus, the Tables 2 and 3 indicate a long-term excess of high values of temperature and enthalpy of outdoor air in Moscow in some years. Therefore, we put forward a proposal to approach the choice of the outdoor air design parameters for the warm period, taking into account the possible durations of their violation [20,21]. We have performed preliminary calculations to estimate the required change in the size of air conditioning units to match their enthalpy values specified in SP 60.13330.2020. The calculations have shown that, taking into account the possibility of regulating the cooling output of the air coolers by changing the coolant consumption or, in extreme cases, by changing the air flow rate in the air cooler by equipping it with a bypass, an increase in the size of the installation is not required. The estimation of the change in the annual cold consumption in individual years requires a more thorough study, which will be carried out later.

\section{Conclusions}

1. Most countries, when rationing the outdoor air climatic parameters of the warm period of the year, proceed from a much smaller non-availability number of hours than the Russian Federation (the USA, Vietnam). In addition, they have more non-availability gradations than the two Russian ones.

2. For the warm period of the year in the Russian climate, it is important to take into account the possible rather long periods of time, when high values of temperature and enthalpy of the outdoor air are observed in individual years. When choosing the outdoor air design parameters for the cold period of the year we take this into account, while processing the initial data for the warm period of the year we follow the countries, which assign the design parameters according a multiyear selection, but they at least take small average long terms of the design value non-availability.

3. The feasibility of shifting to the choice of design parameters of outdoor air temperature and enthalpy in terms of availability from year to year is justified by the large dispersion of the parameters ' values in different years.

4. The offered method of rationing thedesign parameters of outdoor air for the warm period of the year will lead to a certain increase in their values in comparison with the current 
ones. At the same time, there will be a decrease in the time of overshooting of the internal parameters over the design parameters, but, as preliminary calculations show, no significant increase in the size of air conditioning units will be required.

5. The submission form of any design parameter of the external environment should be assigned by the users of this setting, not the climate scientists, who, of course, must deal directly with the processing of the initial climate information, as soon as only they can competently do it.

\section{References}

1. Y. Yu, S. You, H. Zhang, T. Ye, Y. Wang, S. Wei. Renew. and Sustain. En. Rev. V. 141 , 110788 (2021)

2. Z. Han, H. Wei, X. Sun, C. Bai, D. Xue, X. Li. Renew. En. V.160, p. 99-111 (2020)

3. S. Li, Z. Liu, X. Wang. Appl. En. V. 255, 113667 (2019)

4. K. Harby, F. Al-Amri. En. V. 182, p. 321-336 (2019)

5. Yu. A. Tabunshchikov, B. L. Akopov. En. Sav. 4, p. 50-55 (2008)

6. A.I. Burkov, V.S. Ivashkin. Mod. Techn. in Constr. Th. and pr. Vol.1, p. 139-144 (2020)

7. Yu. V. Semenov. AVOK. 2, p. 94-105 (2012)

8. E.G. Malyavina, O.Y. Malikova, L. V. Fam. Izv. Vuz. Str.. V. 1, p.41 - 53 (2019)

9. T. Cholewa, A. Siuta, Olcha, A. Smolarz, P. Muryjas. P. Wolszczak, R. Anasiewicz, C. A.Balaras. En. and Build. V. 236, 110766 (2021)

10. X. He, A. Li, Ya. Ning. Build. and Env. Vol. 167, 106457 (2020)

11. Yo. Cheng, Sh. Zhang, Ch. Huan, M. O. Oladokun, Zh. Lin. Build. and Env. Vol. 147, p. 11-22 (2019)

12. B. Jin, X. Nan, X. Ning, Z. Wang. Sust. C. and Soc. Vol. 53, 101883 (2020)

13. ASHRAE Hanbook - Fund. Ch. 14. Climatic Design Information (2017)

14. T. N. Chấn. Air conditioning. Building Publishing. Hanoi (2002)

15. A. S. Strongin, V. A. Vorontsov, K. A. Kuznetsov. AVOK. 7, p. 20-29 (2020)

16. E.G. Malyavina, L. V. Pham. IOP Conf. Series: Mat. Sc. and Eng. V. 869, 042029 (2020)

17. E.G. Malyavina, O.Y. Malikova., L.V. Pham. IOP Conf. Ser.: Mat. Sc. and Eng. V.365, 022057 (2018)

18. E.G. Malyavina, O.Y. Malikova, P.V. Luong. E3S Web Conf., Top. Pr. of Gr. Arch., Civ. and Env. Eng. (TPACEE 2019). V. 164, 16402008 (2020)

19. The Russian hydrometeorological portal. Hydrometeorological data of the Russian state Fund of data on the state of the natural environment. http://meteo.ru/ (date of access 10.03.2019)

20. E. G. Malyavina, L. V. Pham. Pl., Heat. and Air Cond. V. 2, p.72-75 (2018)

21. E. G. Malyavina, O. Y. Malikova. IOP Conf. Series: Mat. Sc. and Eng. V. 463, 022065 (2018) 